\title{
Inactivation of Staphylococcus aureus and Salmonella enteritidis in tryptic soy broth and caviar samples by high pressure processing
}

\footnotetext{
F. Fioretto ${ }^{1-3}$, C. Cruz ${ }^{1}$, A. Largeteau ${ }^{2}$, T.A. Sarli ${ }^{3}$,

G. Demazeau ${ }^{2}$ and

A. El Moueffak ${ }^{1}$
}

\begin{abstract}
1ERAP, IUT Périgueux, Bordeaux IV, Périgueux, France
${ }^{2}$ Groupe Hautes Pressions, Institut de Chimie de la Matière Condensée de Bordeaux et Ecole Nationale Supérieure de Chimie et de Physique de Bordeaux, Pessac, France 3Department of Inspection of Foods from Animal Origin, University "Federico II" of Naples, Naples, Italy
\end{abstract}

Correspondence

F. Fioretto

ERAP, IUT Périgueux

Bordeaux IV,

Rue Paul Mazy, 39

24019 Périgueux Cedex

France

Fax: +33-5-5306-3143

E-mail: fioretto@unina.it

Presented at the 3rd International Conference on High Pressure

Bioscience and Biotechnology,

Rio de Janeiro, RJ, Brazil,

September 27-30, 2004.

Received January 17, 2005

Accepted May 18, 2005

\begin{abstract}
We studied the action of high pressure processing on the inactivation of two foodborne pathogens, Staphylococcus aureus ATCC 6538 and Salmonella enteritidis ATCC 13076, suspended in a culture medium and inoculated into caviar samples. The baroresistance of the two pathogens in a tryptic soy broth suspension at a concentration of $10^{8}$ $10^{9}$ colony-forming units/ml was tested for continuous and cycled pressurization in the 150- to 550-MPa range and for 15-min treatments at room temperature. The increase of cycle number permitted the reduction of the pressure level able to totally inactivate both microorganisms in the tryptic soy broth suspension, whereas the effect of different procedure times on complete inactivation of the microorganisms inoculated into caviar was similar.
\end{abstract}

\section{Introduction}

The handling of fish products during the manufacturing process involves a risk of contamination with Staphylococcus aureus, a Gram-positive microorganism causing foodborne human intoxication (1). These bacteria are salt-tolerant and therefore can contaminate all cured preparations such as caviar and fish-based preserves.

Salmonella enteritidis is a Gram-negative microorganism inhabiting the intestinal tract of a wide range of animals that can be isolated close to the coast from animal and human waste-polluted waters. For this rea-
Key words

- High pressure processing

- Staphylococcus aureus

- Salmonella enteritidis

- Tryptic soy broth

- Caviar

- Pressure cycles son, fish is frequently contaminated with Salmonella. Generally fish products such as fish eggs are involved in a secondary contamination process. Recent studies have pointed out the increase in the detection of Salmonella in fish products (2) and the incidence of foodborne human diseases caused by Salmonella $(3,4)$.

"Caviar" is the product obtained from fish eggs, separated from the connective tissue of ovaries and subjected to salting, to the addition of additives and sometimes to pasteurization for its preservation. Caviar is a foodstuff of high nutrient value because fish eggs are a rich source of vitamins and min- 
eral nutrients and, on the basis of their amino acid profile, their protein quality is considerable (5). Generally fish eggs do not remain microbiologically sterile after the different procedures involved in caviar fabrication. Egg screening is a critical step during processing which contributes to bacterial contamination due to the lack of proper hygiene often occurring in this case. Caviar can be contaminated with various species of spoilage bacteria, but also with pathogens $(S$. aureus, Salmonella sp, Vibrio sp, Aeromonas sp, Clostridium botulinum) (6). Thus, caviar can pose food safety risks if not properly handled.

Caviar can be pasteurized, but the changes in sensory properties of the thermically treated product are not appreciated by consumers (7). The salt concentration and storage temperature do not always represent preventive measures to preserve caviar. Therefore, it is necessary to add chemical preservatives such as borax because of their antimicrobial effect. New mild technologies are being evaluated for their effectiveness in making caviar safe for consumers and in extending its shelf life. High pressure is an interesting technique for the preservation of caviar, not only because it inactivates pathogens and spoilage bacteria, but also because it can avoid the use of chemical additives such as borax, although its potential risks have not been fully determined.

\section{Material and Methods}

\section{Material}

S. aureus ATCC 6538 and S. enteritidis ATCC 13067 were obtained as freeze-dried pellet cultures in thermosealed vials from Institut Pasteur, Paris, France. These cultures were selected because they are welldefined typed strains which have been used in many previous investigations including high pressure processing (8-10). The vials were stored at freezing temperature until use.
Samples of "caviar d'Aquitaine" (eggs from Siberian sturgeon: Acipenser baerii), free from the additive borax, packaged into 2-part metal tins of $30 \mathrm{~g}$, were obtained from S.C.E.A. Sturgeon, St. Fort sur Gironde, France. Samples of aquacultured trout caviar (eggs from rainbow trouts: Onchorinchus mykiss) in glass jars (about $30 \mathrm{~g}$ ) were provided by Viviers de France, Sarrance (France). The samples were stored at $0-4^{\circ} \mathrm{C}$ until use.

\section{Preparation of bacterial suspensions in tryptic soy broth solution}

The cultures were rehydrated by the addition of $0.3 \mathrm{ml}$ tryptic soy broth (TSB, Merck, Darmstadt, Germany) and stock cultures of both strains were then prepared on tryptic soy agar (Difco, Detroit, MI, USA), incubated at $37^{\circ} \mathrm{C}$ for $24 \mathrm{~h}$ and stored at $4^{\circ} \mathrm{C}$. To revive the microorganisms, a single pellet of the cultures was resuspended in $5 \mathrm{ml}$ $\mathrm{TSB}$, followed by incubation at $37^{\circ} \mathrm{C}$ for 48 h. Further dilutions in TSB were necessary to achieve a concentration of approximately $10^{8}-10^{9}$ colony-forming units (CFU)/ml $S$. aureus ATCC 6538 and S. enteritidis ATCC 13076 at the beginning of high pressure processing. To determine that the microbial load was in the same range for each assay, absorbance at $600 \mathrm{~nm}$ was checked with a spectrophotometer. The cell suspensions $(25 \mathrm{ml})$ were vacuum sealed in double sterile polyethylene pouches (PA/PE 20/70 $\mu \mathrm{m})$ and subjected to the high-pressure treatments.

\section{Caviar inoculated with Staphylococcus aureus and Salmonella enteritidis}

The assays were carried out separately for the broth culture of each strain. A 1-ml cell suspension was added to $25 \mathrm{~g}$ of caviar and the mixture was gently shaken by hand for $5 \mathrm{~min}$. The inoculated samples were vacuum sealed in double sterile polyethylene pouches (PA/PE 20/70 $\mu \mathrm{m}$ ) and sub- 
jected to high pressure processing. Each treatment was carried out in duplicate.

High pressure processing

The equipment used for high pressure processing was a discontinuous isostatic press specifically used for applications in the food science field at IHP ("Interface Hautes Pressions") - ENSCPB ("Ecole Nationale Supérieure de Chimie et de Physique"), University Bordeaux I: Sciences and Technologies, France. The hyperbaric apparatus (NFMTechnologies, Le Creusot, France) and the Framatome device (Paris, France) commercialized by Clextral (Firminy, France) are designed to attain a maximum pressure of $800 \mathrm{MPa}$. Pressure and temperature were constantly monitored and recorded during the process. Water was used as the pressurization fluid.

\section{Objective of our study and parameters of high pressure processing}

The aim of the present investigation was to study the application of high-pressure treatments able to destroy a large load of pathogens potentially present in fish eggs, and to find the optimal pressure levels necessary to preserve the organoleptic characteristics of fresh caviar. Duplicate samples of S. aureus ATCC 6538 and S. enteritidis ATCC 13076 in TSB suspension were subjected to pressure treatments in the 150-550 $\mathrm{MPa}$ and 150-450 MPa range, respectively, at room temperature for different times (15 $\min , 5 \min x 3$ cycles, 3 min $x 5$ cycles, 2 min $x 7$ cycles). The pressure used for the treatment of caviar samples inoculated with $S$. aureus ATCC 6538 was $500 \mathrm{MPa}$ at room temperature for $15 \mathrm{~min}$ and $450 \mathrm{MPa}$ for 3 cycles of $5 \mathrm{~min}$, whereas the caviar samples inoculated with S. enteritidis ATCC 13076 were pressurized at $400 \mathrm{MPa}$ at room temperature for $15 \mathrm{~min}$ and at $350 \mathrm{MPa}$ for $5 \mathrm{~min}$ for 3 cycles. For these experiments the choice of the pressure values was based on the analysis of preliminary results obtained for TSB suspensions subjected to only two pressurization times (15 min, 5 min x 3 cycles). Five hundred and $400 \mathrm{MPa}$ were the pressures able to destroy S. aureus and S. enteritidis, respectively, after a treatment of 15 min, while 450 and $350 \mathrm{MPa}$ were the lethal pressures for the treatment of $5 \mathrm{~min}$ for 3 cycles. All high-pressure treatments were tested twice. Control samples were held at atmospheric pressure. After processing, all samples were stored at refrigeration temperature until analysis.

\section{Enumeration of viable cells by microbiological analysis of tryptic soy broth suspension samples}

Appropriate 10-fold serial dilutions $\left(10^{-8}\right)$ were made in sterile-buffered peptone-water (AES Laboratoire, Route de Dol, Combourg, France). One milliliter of each dilution was plated onto plate count agar (AES Laboratoire) in duplicate. The plates were incubated at $37^{\circ} \mathrm{C}$ for $72 \mathrm{~h}$ and the average number of colonies from the duplicate plates was recorded for each sample. The number of survivors was reported as $\log \mathrm{CFU} / \mathrm{ml}$.

\section{Inoculated caviar samples}

Twenty-five grams of each sample and $225 \mathrm{ml}$ of buffered peptone water were homogenized using a Stomacher ${ }^{\circledR}$. Further 10fold dilutions $\left(10^{-8}\right)$ were made in sterilebuffered peptone water (AES Laboratoire) and $0.1 \mathrm{ml}$ of each dilution was plated in duplicate onto selective media: Baird-Parker (AES Laboratoire) for the enumeration of $S$. aureus ATCC 6538 and Rambach (from Merck) for the enumeration of $S$. enteritidis ATCC 13076. The plates were incubated at $37^{\circ} \mathrm{C}$ for $24-48 \mathrm{~h}$. The average number of colonies on the duplicate plates was then recorded for each sample. The number of survivors is reported as $\log \mathrm{CFU} / \mathrm{g}$. 


\section{Results and Discussion}

Effect of high pressure on Staphylococcus aureus ATCC 6538 in tryptic soy broth suspension

In order to study the effect of high pressure on S. aureus ATCC 6538 and Salmonella enteritidis ATCC 13076 suspended in TSB solution and to evaluate their inactivation rate, the number of viable cells in the untreated suspensions $\left(\mathrm{N}_{0}\right)$ and the number of viable cells in the pressurized suspensions (N) were defined during every experiment, corresponding to the average of the values obtained for duplicate samples. The destructive effectiveness (DE) of high pressure in inactivating the pathogen strains is expressed by $(\mathrm{DE})=-\log \left(\mathrm{N} / \mathrm{N}_{0}\right)=\log \mathrm{N}_{0}-\log \mathrm{N}$.

The rate of microorganisms able to survive the treatment is reported by the $\mathrm{N} / \mathrm{N}_{0}$ ratio which in our study ranged from 1 to $10^{9}$. The DE of high-pressure treatment is shown in the graphs in Figures 1 and 2 and is

Figure 1. Inactivation of Staphylococcus aureus ATCC 6538 inoculated into tryptic soy broth at different pressures and treatment times.

Figure 2. Inactivation of Salmonella enteritidis ATCC 13076 inoculated into tryptic soy broth at different pressures and treatment times.
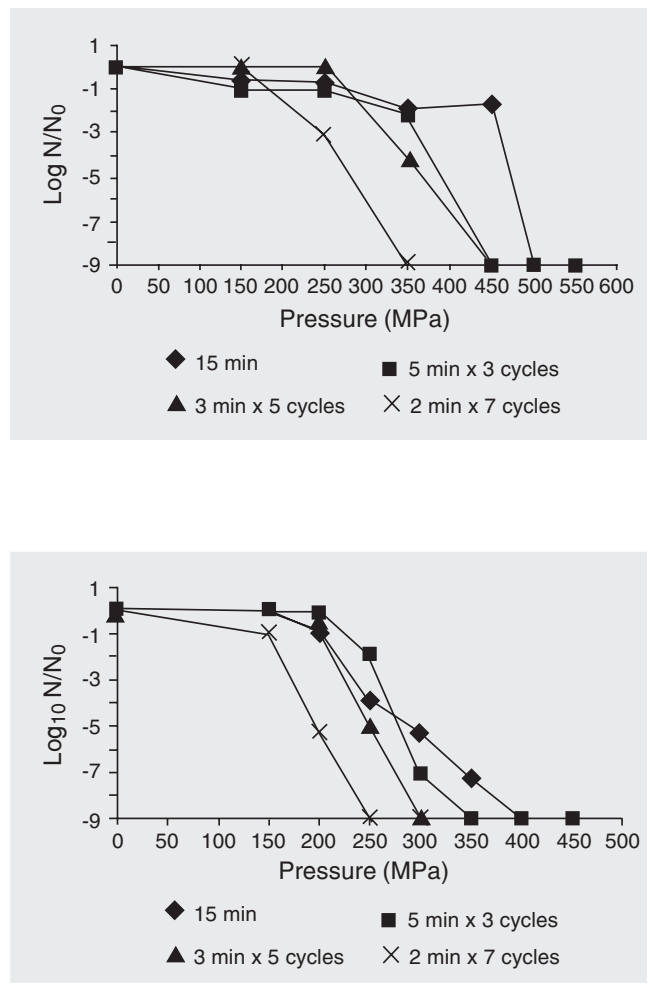

correlated with pressure and with treatment times. For S. aureus ATCC 6538 the inactivation rates after treatment for $15 \mathrm{~min}$ at 150, 350, 450, and $500 \mathrm{MPa}$ were 0.7, 1.9, 1.7 , and $8.9 \log _{10}$, respectively. We observed a destruction threshold value of $500 \mathrm{MPa}$, with no significant destruction occurring up to this pressure. In the $150-450 \mathrm{MPa}$ range, only some threshold values of weak $S$. aureus inactivation resulted. These results indicate the high baroresistance of $S$. aureus ATCC 6538. Some studies have also shown the high resistance to continuous pressure of other strains of $S$. aureus. Patterson et al. (11) applied $700 \mathrm{MPa}$ for $15 \mathrm{~min}$ at $20^{\circ} \mathrm{C}$ to S. aureus NCTC 10652 in phosphate buffer and obtained an inactivation of more than 5 $\log _{10}$. O'Reilly et al. (8) had to use a pressure of $600 \mathrm{MPa}$ at room temperature for $20 \mathrm{~min}$ in order to achieve a $4-\log _{10}$ reduction in counts of S. aureus ATCC 6538. On the basis of the results concerning the continuous pressure treatments, in a second step of our study we carried out different treatments in cycles in order to identify the one that combined the features of high DE and the ability to preserve the organoleptic qualities of fresh caviar. The reduction rates for $S$. aureus ATCC 6538 are reported in Table 1. The loss of viability in counts performed after 3 pressure cycles of $5 \mathrm{~min}\left(20^{\circ} \mathrm{C}\right)$ was 1 , 2.2 , and $8.85 \log _{10}$, respectively, at 150,350 , and $450 \mathrm{MPa}$. For 5 pressure cycles of $3 \mathrm{~min}$ $\left(20^{\circ} \mathrm{C}\right)$ the inactivation rates increased only at $350 \mathrm{MPa}$ and resulted in $4.15 \log _{10}$. When the number of cycles was increased further, the inactivation rate of $S$. aureus was greater also at lower pressures. In fact, after 7 cycles of 2 min the inactivation rates were 3.1 and $8.85 \log _{10}$, respectively, at 250 and $350 \mathrm{MPa}$. The inactivation rates of $S$. aureus for continuous and cycling pressure treatments are illustrated in Figure 1. The data agree with the results reported by Rigaldie (9), who showed that 3 cycles of $10 \mathrm{~min}$ at $500 \mathrm{MPa}$ and at room temperature were sufficient to obtain a $6.6-\log _{10}$ reduction, while 6 cycles 
of 5 min completely destroyed $S$. aureus (8.6 $\log _{10}$ ). Under the same conditions of pressure and temperature, for a continuous treatment of $30 \mathrm{~min}$ the loss of microorganism viability was only $1.42 \log _{10}$. After electron microscopy analysis of the changes occurring in cells after pressurization, the author observed irreversible modifications of the intracellular material and also a perturbation in cell division concerning the septum and the cell membrane (9). These phenomena can explain the lethal effect of pressure cycles on the microorganisms. Processing conditions (pressure, temperature, time), microorganism strain, and the kind of substrate (composition, $\mathrm{pH}, \mathrm{Aw}$ ) obviously influence the inactivation caused by pressure treatment. In general, the sensitivity of microorganisms to pressure is lower in foods than in buffer suspensions (11) and can depend on the food type $(12,13)$.

\section{Effect of high pressure on Salmonella} enteritidis ATCC 13076 in tryptic soy broth suspension

The effect of high pressure in a continuous 15-min treatment on S. enteritidis ATCC 13076 in TSB suspension was obtained in the 150-450 MPa range. The choice of this range was based on literature data $(14,15)$ showing that $S$. enteritidis is less baroresistant than $S$. aureus. Based on these preliminary results, the study was carried out in the same way as in the experiments on $S$. aureus, with the application of various pressure cycles. Figure 2 and Table 2 present the inactivation rates of $S$. enteritidis after continuous and cycling pressure treatments. The total destruction of $S$. enteritidis was obtained for 3 , 5 , and 7 cycles, respectively, at 350, 300, and $250 \mathrm{MPa}$. The increase of cycle numbers permitted us to reduce the pressure level needed to destroy S. enteritidis. The effectiveness of the pressure cycles is evident when compared to continuous pressure under the same treatment conditions. Few studies have been done about the effect of high pressure processing on $S$. enteritidis, which is the main food poisoning Salmonella serotype. Ponce et al. (16) tested various behaviors of $S$. enteritidis inoculated into egg-based medium at different pressure (350 and $450 \mathrm{MPa}$ ), temperature and time levels. The best results for the process were observed at $50^{\circ} \mathrm{C}$. Two or three cycles of 5 min achieved higher destruction than continuous treatment of the same total duration. Pressure cycles enhanced $S$. enteritidis sensitivity to pressure. Yuste et al. (17) found a reduction in $S$. enteritidis counts between 7.2 and $7.7 \log _{10}$ in poultry sausages processed at $500 \mathrm{MPa}$ by combining different times (10-30 $\mathrm{min}$ ) and temperatures (50$70^{\circ} \mathrm{C}$ ). Patterson et al. (11) treated S. enteritidis $\mathrm{FDA}$ at $450 \mathrm{MPa}$ for $15 \mathrm{~min}\left(20^{\circ} \mathrm{C}\right)$ in phosphate-buffered saline suspension and obtained a $5-\log _{10}$ reduction in counts.

The results of the present study underline

\begin{tabular}{|c|c|c|}
\hline $\begin{array}{l}\text { Pressure } \\
\text { (MPa) }\end{array}$ & $\begin{array}{c}\text { Duration ( } \min x \\
\text { number of cycles) }\end{array}$ & $\begin{array}{l}\text { Reduction rate } \\
\left(\log _{10} \text { CFU/ml) }\right.\end{array}$ \\
\hline \multirow[t]{4}{*}{150} & $15 \times 1$ & 0.7 \\
\hline & $5 \times 3$ & 1.0 \\
\hline & $3 \times 5$ & 0.0 \\
\hline & $2 \times 7$ & 3.1 \\
\hline \multirow[t]{4}{*}{350} & $15 \times 1$ & 1.9 \\
\hline & $5 \times 3$ & 2.2 \\
\hline & $3 \times 5$ & 4.15 \\
\hline & $2 \times 7$ & ND \\
\hline \multirow[t]{4}{*}{450} & $15 \times 1$ & 1.7 \\
\hline & $5 \times 3$ & ND \\
\hline & $3 \times 5$ & ND \\
\hline & $2 \times 7$ & ND \\
\hline \multirow[t]{4}{*}{500} & $15 \times 1$ & ND \\
\hline & $5 \times 3$ & ND \\
\hline & $3 \times 5$ & ND \\
\hline & $2 \times 7$ & ND \\
\hline \multirow[t]{4}{*}{550} & $15 \times 1$ & ND \\
\hline & $5 \times 3$ & ND \\
\hline & $3 \times 5$ & ND \\
\hline & $2 \times 7$ & ND \\
\hline
\end{tabular}

$\mathrm{CFU}=$ colony-forming unit; $\mathrm{ND}=$ non-detected . 
Table 2. High pressure inactivation of Salmonella enteritidis ATCC 13076 in tryptic soy broth at $20^{\circ} \mathrm{C}$ at different pressures and for different times.

\begin{tabular}{|c|c|c|}
\hline $\begin{array}{l}\text { Pressure } \\
(\mathrm{MPa})\end{array}$ & $\begin{array}{l}\text { Duration ( } \min x \\
\text { number of cycles) }\end{array}$ & $\begin{array}{l}\text { Reduction rate } \\
\left(\log _{10} \mathrm{CFU} / \mathrm{ml}\right)\end{array}$ \\
\hline \multirow[t]{4}{*}{150} & $15 \times 1$ & 0.00 \\
\hline & $5 \times 3$ & 0.00 \\
\hline & $3 \times 5$ & 1.00 \\
\hline & $2 \times 7$ & 1.00 \\
\hline \multirow[t]{4}{*}{200} & $15 \times 1$ & 0.94 \\
\hline & $5 \times 3$ & 0.15 \\
\hline & $3 \times 5$ & 0.70 \\
\hline & $2 \times 7$ & 5.30 \\
\hline \multirow[t]{4}{*}{250} & $15 \times 1$ & 3.94 \\
\hline & $5 \times 3$ & 1.95 \\
\hline & $3 \times 5$ & 5.00 \\
\hline & $2 \times 7$ & ND \\
\hline \multirow[t]{4}{*}{300} & $15 \times 1$ & 5.36 \\
\hline & $5 \times 3$ & 7.07 \\
\hline & $3 \times 5$ & ND \\
\hline & $2 \times 7$ & ND \\
\hline \multirow[t]{4}{*}{350} & $15 \times 1$ & 7.26 \\
\hline & $5 \times 3$ & ND \\
\hline & $3 \times 5$ & ND \\
\hline & $2 \times 7$ & ND \\
\hline \multirow[t]{4}{*}{400} & $15 \times 1$ & ND \\
\hline & $5 \times 3$ & ND \\
\hline & $3 \times 5$ & ND \\
\hline & $2 \times 7$ & ND \\
\hline \multirow[t]{4}{*}{450} & $15 \times 1$ & ND \\
\hline & $5 \times 3$ & ND \\
\hline & $3 \times 5$ & ND \\
\hline & $2 \times 7$ & ND \\
\hline
\end{tabular}

$\mathrm{CFU}=$ colony-forming unit; $\mathrm{ND}=$ non-detected .
Table 3. Behavior of Staphylococcus aureus ATCC 6538 inoculated into caviar samples after high-pressure treatments.

\begin{tabular}{lccc}
\hline Sample & $\mathrm{MPa} / \mathrm{min}$ & $\mathrm{CFU} / \mathrm{g}$ & $\log _{10} \mathrm{CFU} / \mathrm{g}$ \\
\hline $\begin{array}{l}\text { Sturgeon caviar } \\
\text { Control }\end{array}$ & 0 & $30.510^{3}$ & 4.50 \\
Treated & $500 / 15$ & $<10$ & $<1$ \\
Treated & $450 / 5 \times 3$ cycles & $<10$ & $<1$ \\
& & & \\
Trout caviar & 0 & $4610^{3}$ & 4.66 \\
Control & $500 / 15$ & $<10$ & $<1$ \\
Treated & $450 / 5 \times 3$ cycles & $<10$ & $<1$ \\
Treated & & & \\
\hline
\end{tabular}

$\mathrm{CFU}=$ colony-forming unit. the higher baroresistance of $S$. aureus ATCC 6538 compared to $S$. enteritidis ATCC 13076 and the effectiveness of pressure cycles in the destruction of both pathogens at weak pressure levels. Using several cycles it was possible to reduce the pressure able to inactivate high loads of $S$. aureus and $S$. enteritidis $\left(10^{8}-10^{9} \mathrm{CFU} / \mathrm{ml}\right)$. In fact, after 7 pressure cycles of $2 \mathrm{~min}$ at room temperature the total destruction of the pathogens in TSB suspension was obtained at 350 and 250 $\mathrm{MPa}$, respectively. The destruction threshold value was high especially in the case of S. aureus ATCC 6538 for the continuous treatment, while for S. enteritidis ATCC 13076 this phenomenon did not occur. The different features of the two microorganisms could explain our results.

\section{Destruction by high pressure of Staphylococcus aureus and Salmonella enteritidis inoculated into caviar}

Based on the analysis of preliminary results of the TSB models, the pressurization of caviar samples inoculated with $S$. aureus ATCC 6538 and S. enteritidis ATCC 13076 was carried out at the threshold values obtained for the suspensions for the 15-min treatment and for 3 pressure cycles of $5 \mathrm{~min}$ at room temperature. The effect of highpressure treatments on the strains inoculated into caviar is shown in Tables 3 and 4. For the samples inoculated with $S$. aureus ATCC 6538 , both pressure treatments $(450 \mathrm{MPa} / 5$ min $x 3$ cycles and $500 \mathrm{MPa} / 15 \mathrm{~min}$ ) significantly reduced the counts.

Also the number of $S$. enteritidis ATCC 13076 inoculated into caviar samples, obtained after pressurization, were $<2 \log \mathrm{CFU} /$ $\mathrm{g}$ for the continuous treatments $(400 \mathrm{MPa} / 15$ min) and for the treatments in cycles (350 $\mathrm{MPa} / 5 \mathrm{~min} \mathrm{x} 3$ cycles). Thus, at the pressure levels used for the experiments no difference was found between the continuous and cycling treatments. In addition, the substrate did not affect the effect of high pressure 
processing on the microorganisms.

The present results confirm that treatments in cycles improve the effect of pressure on S. aureus and Salmonella enteritidis. Also, the application of cycles permitted us to reduce the pressure level necessary to preserve the sensory properties of caviar. Therefore, high pressure processing represents an interesting procedure for microbial stabilization in fish products because it can eliminate pathogens or spoilage bacteria, potentially present in the product, and can also reduce the use of chemical preservatives which have potential and still undetermined risks.

\section{Perspectives}

Our study of the inactivation of $S$. aureus ATCC 6538 and S. enteritidis ATCC 13076 in caviar samples has raised different problems involving both basic science and food processing. In order to obtain an explanation
Table 4. Behavior of Salmonella enteritidis ATCC 13076 inoculated into caviar samples after high-pressure treatments.

\begin{tabular}{lccc}
\hline Sample & $\mathrm{MPa} / \mathrm{min}$ & $\mathrm{CFU} / \mathrm{g}$ & $\log _{10} \mathrm{CFU} / \mathrm{g}$ \\
\hline $\begin{array}{c}\text { Sturgeon caviar } \\
\text { Control }\end{array}$ & 0 & & \\
Treated & $400 / 15$ & $13.510^{5}$ & 6.10 \\
Treated & $350 / 5 \times 3$ cycles & $<100$ & $<2$ \\
Trout caviar & & & $<2$ \\
$\quad$ Control & 0 & $5610^{3}$ & 4.74 \\
Treated & $400 / 15$ & $<100$ & $<2$ \\
Treated & $350 / 5 \times 3$ cycles & $<100$ & $<2$ \\
\hline CFU $=$ colony-forming unit. & & &
\end{tabular}

about the pressure behavior in caviar an investigation will be conducted on the proteins. In addition, the role of cycling pressure compared to continuous pressure must be investigated. In parallel, regarding food processing conditions, it would be necessary to reduce the pressure level and consequently improve the efficiency of cycling processes.

\section{References}

1. Varnam AH \& Evans MG (1991). Foodborne Pathogens - An Illustrated Text. Wolfe Publishing, London, England.

2. Heinitz ML, Ruble RD, Wagner DE et al. (2000). Incidence of Salmonella in fish and seafood. Journal of Food Protection, 63: 579-592.

3. Davies AR, Capell C, Jehanno D et al. (2001). Incidence of foodborne pathogens on European fish. Food Control, 12: 67-71.

4. Liston J (1990). Microbial hazards of seafood consumption. Food Technology, 44: 56, 58-62.

5. Sternin V \& Dorè I (1998). Le Caviar. De la Pêche au Grain. Ed. INRA, Paris, France.

6. Altug G \& Bayrak Y (2003). Microbiological analysis of caviar from Russia and Iran. Food Microbiology, 20: 83-86.

7. Bledsoe GE (2003). Caviar and fish roe products. CRC Critical Reviews in Food Science and Nutrition, 43: 317-356.

8. O'Reilly CE, O'Connor PM, Kelly AL et al. (2000). Use of hydrostatic pressure for inactivation of microbial contaminants in cheese. Applied and Environmental Microbiology, 66: 4890-4896.

9. Rigaldie $Y$ (2002). Sur l'impact des traitements sous hautes pressions dans la décontamination et la stérilisation de formes pharmaceutiques renfermant des molecules thérapeutiques sensibles aux procédés énergetiques. Doctoral thesis, Université Bordeaux 1, France.

10. Masschalck $B$, van Houdt $R$, van Haver EGR et al. (2001). Inactivation of Gram negative bacteria by lysozyme, denatured lysozyme, and lysozyme-derived peptides under high hydrostatic pressure. Applied and Environmental Microbiology, 67: 339-344.
11. Patterson MF, Quinn M, Simpson R et al. (1995). Sensitivity of vegetative pathogens to high hydrostatic pressure treatment in phosphate-buffered saline and foods. Journal of Food Protection, 58: 524-529.

12. Patterson MF \& Kilpatrick DJ (1998). The combined effect of high hydrostatic pressure and mild heat on inactivation of pathogens in milk and poultry. Journal of Food Protection, 61: 432-436.

13. Gervilla R, Ferragut V \& Guamis B (2000). High pressure inactivation of microorganisms inoculated into ovine milk of different fat contents. Journal of Dairy Science, 83: 674-682.

14. Alpas $H$, Kalchayanand N, Bozoglu $F$ et al. (1999). Variation in resistance to hydrostatic pressure among strains of foodborne pathogens. Applied and Environmental Microbiology, 65: 4248-4251.

15. Alpas H \& Bozoglu $F(2000)$. The combined effect of high hydrostatic pressure, heat and bacteriocins on inactivation of foodborne pathogens in milk and orange juice. World Journal of Microbiology and Biotechnology, 16: 387-392.

16. Ponce E, Pla R, Sendra E et al. (1999). Destruction of Salmonella enteritidis inoculated in liquid whole egg by high hydrostatic pressure: a comparative study in selective and non selective media. Food Microbiology, 16: 357-365.

17. Yuste J, Pla R \& Mor-Mur M (2000). Salmonella enteritidis and aerobic mesophiles in inoculated poultry sausages manufactured with high-pressure processing. Letters in Applied Microbiology, 31: 374-377. 